\title{
CRIMEN TRANSNACIONAL ORGANIZADO: LAS ORGANIZACIONES DEL NARCOTRÁFICO MEXICANO EN COLOMBIA
}

Darío Enrique Cortés Castillo

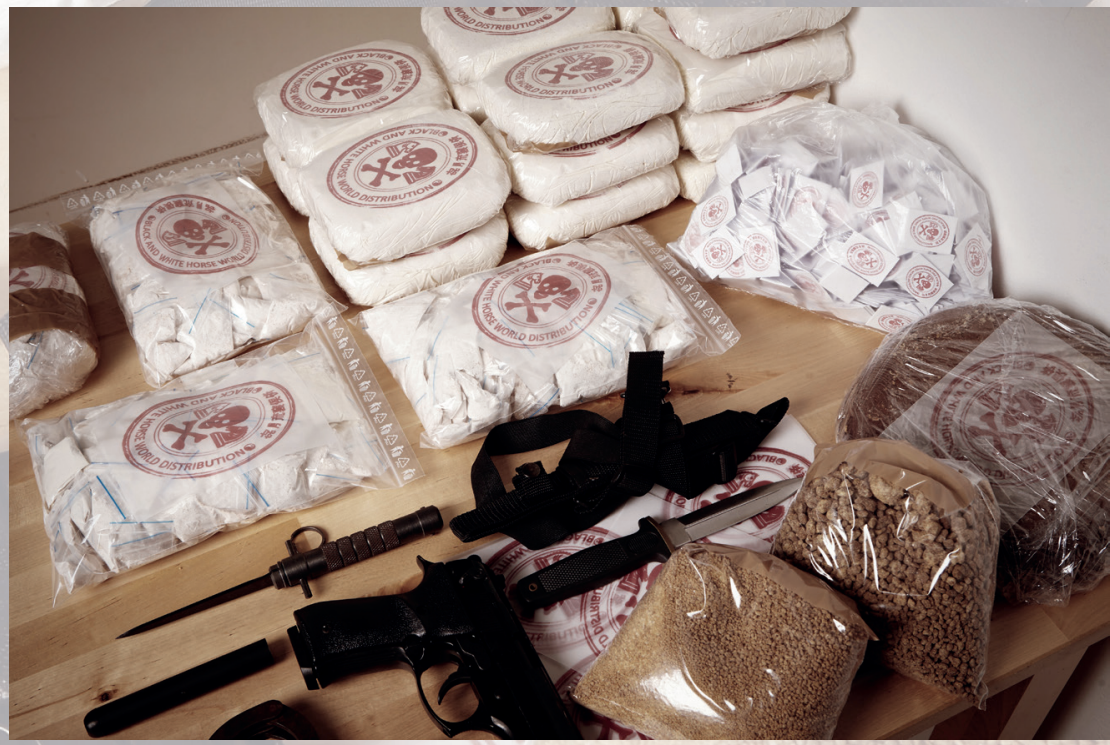





\title{
CRIMEN TRANSNACIONAL ORGANIZADO: LAS ORGANIZACIONES DEL NARCOTRÁFICO MEXICANO EN COLOMBIA*
}

\author{
Darío Enrique Cortés Castillo \\ Escuela Superior de Guerra "Rafael Reyes Patria”
}

\section{Resumen}

Tras varios años de relaciones entre organizaciones criminales transnacionales de Colombia y México, los carteles mexicanos, con el propósito de ampliar los territorios de influencia y utilidades sobre el negocio ilícito, tomaron la determinación de expandir sus actividades hacia territorio colombiano. Proyectaron sacar grandes réditos, al valerse de la existencia de organizaciones armadas al margen de la ley, carteles del narcotráfico y grupos armados organizados (en adelante, GAO) que actúan en un vasto territorio con débil presencia del Estado y Gobiernos vecinos proclives al negocio ilícito. A partir de esta hipótesis, el presente estudia el fenómeno de convergencia y, apoyado en la línea del tiempo y en fuentes primarias, entre las que destacan los documentos emitidos por la Oficina contra la droga y el delito de la Organización de Naciones Unidas (UNODC), documentos internos de las FARC, declaraciones y estudios especializados, se fundamentará la tipificación del crimen transnacional organizado y el narcotráfico como una amenaza para la humanidad. Se avanza hacia la identificación, en la línea del tiempo, de las relaciones entre los carteles colombianos y mexicanos y luego se verifican, desde el fenómeno de convergencia, los vínculos transnacionales entre los carteles mexicanos del narcotráfico con las organizaciones insurgentes, terroristas y criminales de Colombia. Por último se abordan las implicaciones que tal relación puede tener sobre la seguridad regional.

Palabras clave: crimen, narcotráfico, convergencia, GAO, transnacional.

El autor: magíster en inteligencia estratégica y prospectiva, y magíster en inteligencia estratégica Cargo, en Escuela Superior de Guerra "Rafael Reyes Patria". Correo electrónico: cortesd@esdegue.edu.co

Recibido: 5 de marzo de 2020; evaluado: 30 de marzo de 2020; aceptado: 10 de abril de 2020.

Artículo de investigación que expone resultados de investigación del proyecto titulado: "Las fuerzas militares de Colombia ante el macro delito en el diseño de políticas de seguridad y defensa nacional", del grupo de investigación Masa Crítica, reconocido y categorizado como C por Colciencias y registrado con el código COL0123247, adscrito a la Escuela Superior de Guerra "General Rafael Reyes Prieto". 


\title{
ORGANIZED TRANSNATIONAL CRIME: MEXICAN DRUG TRAFFICKING ORGANIZATIONS IN COLOMBIA
}

\author{
Darío Enrique Cortés Castillo \\ Escuela Superior de Guerra "Rafael Reyes Patria"
}

\begin{abstract}
After several years of relations between transnational criminal organizations in Colombia and Mexico, Mexican cartels decided to expand their activities into Colombian territory to expand their territories of influence and profit from the illicit business. The cartels also sought to take advantage of the existence of illegal armed organizations, drug trafficking cartels, and organized armed groups (hereinafter OAGs) that act in a vast territory where State presence is weak and in border areas where neighboring governments are prone to illicit business, which makes their intentions a priority objective. This article supports this hypothesis through qualitative research, the study of the convergence phenomenon, the timeline as a basis and working guide, and primary sources, including documents issued by the Contra Office. The article supports the classification of organized transnational crime and drug trafficking as a threat to humanity based on documents from the United Nations Office on Drug and Crime (UNODC), internal documents of the FARC, declarations, and specialized studies. The article then uses a timeline to describe the relationship between Colombian and Mexican cartels and then uses the phenomenon of convergence to establish the transnational ties between Mexican drug trafficking cartels and Colombian insurgent, terrorist, and criminal organizations. Finally, the article closes by reflecting on the implications the relationship between insurgent movements, criminal organizations, and terrorists may have on regional security.
\end{abstract}

Keywords: crime, drug trafficking, convergence, OAG, transnational.

Author: master's in strategic and prospective intelligence, master's in Cargo strategic intelligence, Rafael Reyes Patria War College. Email: cortesd@esdegue.edu.co

Received: March 5, 2020; evaluated: March 30, 2020; accepted: April 10, 2020. 


\title{
CRIME TRANSNACIONAL ORGANIZADO: AS ORGANIZAÇÕES DO NARCOTRÁFICO MEXICANO NA COLÔMBIA
}

\author{
Darío Enrique Cortés Castillo \\ Escuela Superior de Guerra "Rafael Reyes Patria”
}

\section{Resumo}

Após vários anos de relações entre organizações criminosas transnacionais da Colômbia e do México, os cartéis mexicanos, com o objetivo de ampliar os territórios de influência e o lucro sobre o negócio ilegal, tomaram a determinação de expandir suas atividades ao território colombiano. Planejaram tirar grandes proveitos a partir da existência de organizações armadas à margem da lei, cartéis do narcotráfico e grupos armados que atuam em um amplo território com fraca presença do Estado e com governos vizinhos que tendem ao negócio ilícito. A partir disso, estuda-se o fenômeno de convergência e, apoiado na linha do tempo e em fontes primárias, entre as quais se destacam os documentos emitidos pelo Escritório das Nações Unidas sobre Drogas e Crime, os documentos internos das Forças Armadas Revolucionárias da Colômbia, as declarações e os estudos especializados, fundamenta-se a tipificação do crime transnacional organizado e do narcotráfico como uma ameaça para a humanidade. Avança-se à identificação, na linha do tempo, das relações entre os cartéis colombianos e mexicanos, e, em seguida, verifica-se, a partir do fenômeno de convergência, os vínculos transnacionais entre os cartéis mexicanos do narcotráfico com as organizações insurgentes, terroristas e criminosas da Colômbia. Por último, abordam-se as consequências que essa relação pode trazer para a segurança regional.

Palavras-chave: crime, narcotráfico, convergência, grupos armados organizados (GAO), transnacional.

O autor: mestre em inteligência estratégica e prospectiva, e mestre em inteligência estratégica Cargo, Escuela Superior de Guerra "Rafael Reyes Patria". E-mail: cortesd@esdegue.edu.co

Recebido: 5 de março de 2020; avaliado: 30 de março de 2020; aceito: 10 de abril de 2020. 


\section{Introducción}

Por más de cinco décadas, los Gobiernos del hemisferio occidental han luchado contra los diversos eslabones que comprenden el narcotráfico, desde los cultivos de uso ilícito, la producción, la comercialización y el consumo, combatiendo a las organizaciones delincuenciales que se afincaban o transitaban en su territorio, con algunos progresos en su contención. Sin embargo, el fenómeno de la globalización de la economía, caracterizada por la interdependencia de las relaciones políticas económicas y culturales, en la dinámica del comercio exterior absoluto, trajo aparejados serios riesgos para la seguridad de los Estados, al debilitar su intervención en el control de flujos de activos, capitales y fronteras. De tales oportunidades, en la región, las organizaciones del crimen transnacional obtienen los mejores beneficios. ${ }^{1}$

En este contexto, las organizaciones mexicanas del narcotráfico sacan provecho de las ventajas que les dan las circunstancias del entorno global y lanzaron sus tentáculos hacia Colombia, pues su posición y sus condiciones geográficas, las complejidades políticas y sociales, así como la presencia de carteles del narcotráfico, organizaciones insurgentes, organizaciones criminales y grupos armados organizados (en adelante, $\mathrm{GAO}$ ), aunados a la permisividad del Gobierno venezolano con las expresiones del crimen transnacional, la ubican como el territorio ideal para expandir su lucrativo negocio del crimen en la región.

La selección de la base de operaciones no fue hecha a la ligera. Los capos mexicanos la escogieron, como lo expone Duncan, por sus condiciones de subdesarrollo y una imbricación entre conflicto y posconflicto en el que la autoridad gubernamental puede ser evadida y socavada. ${ }^{2}$

La incursión de los carteles mexicanos de Sinaloa, de Tijuana, Nueva Generación, Los Zetas, de Juárez y del Golfo en Colombia se hace más expedita, en razón a los vínculos históricos de las organizaciones aztecas con los otrora carteles de Cali y Medellín, así como los establecidos con las antiguas Fuerzas Armadas Revolucionarias de Colombia, Ejército del Pueblo (en adelante, FARC-EP).

Darío Cortés, "Globalización y su relación con el riesgo del lavado de activos", Revista de las fuerzas armadas 2016, núm. 234 (enero 2016): 39.

2 Ducan Deville, "The Illicit Supply Chain" en Convergence Illicit Networks and National Security in the Age of Globalization, eds. Michael Miklaucic y Jacqueline Brewer (Washington: Center for Complex Operations Institute for National Strategic Studies, 2013), 64. 


\section{Crimen transnacional organizado}

Sin necesidad de remontarse a explicaciones y referencias pretéritas, hasta finales de la década del ochenta, el fenómeno del crimen transnacional organizado se manifestó mediante acuerdos coyunturales entre organizaciones con intereses en común, lo que no significó mayor preocupación para la seguridad y estabilidad de los Estados. Sin embargo, la dinámica entre las organizaciones del crimen transnacional organizado, en el escenario de la globalización, dio un salto cualitativo, al establecer acuerdos y alianzas estratégicas que garantizaran el posicionamiento y la estabilidad de las relaciones. Para el caso colombiano, las primeras expresiones se concretaron a partir de 1994, con los acuerdos entre las mafias neoyorkinas de la familia Gambino y las mafias colombianas, rusas, chinas y japonesas para ordenar el tráfico de drogas en Europa Occidental y evitar la saturación de las rutas. ${ }^{3}$

Hacia 1988, con los vínculos establecidos entre el cartel de Medellín y la Cosa Nostra, mediante el envió de 556 kilos de cocaína a Italia, se buscó hacer de la mafia siciliana la organización que controlara el tráfico de cocaína en Europa Occidental. ${ }^{4}$ Con estos primeros logros, el cartel colombiano avanzó sobre los pactos con la Camorra, con los cuales pretendía compartir los negocios de explotación de las rutas y distribución de la cocaína en Europa. ${ }^{5}$

La magnitud de los acuerdos y convenios — que comprendían actividades lícitas e ilícitas - les permitió a las organizaciones del crimen transnacional acumular ingentes cifras de dinero, cuya cantidad llegaba a superar el producto interno bruto de muchos países, lo que abría las posibilidades de influir, mediante la corrupción, en los destinos de muchas Naciones del mundo. ${ }^{6}$

La dinámica del crimen transnacional y las nefastas consecuencias que traía para los Estados condujeron a las Naciones Unidas a emitir, en el año 2000, en Palermo (Italia), la Convención de las Naciones Unidas contra la delincuencia organizada transnacional (Convención de Palermo), con la cual la comunidad internacional demostró el firme propósito de atender un problema del orden mundial con una respuesta equivalente. Para el secretario general, Kofi Annan, las organizaciones terroristas, traficantes de drogas y tratantes de personas, y otros grupos criminales

Fernando Bermejo, "La globalización del crimen organizado", Eguzkilore 1, núm. 23 (diciembre 2009): 101.

Bermejo, "La globalización del crimen organizado", 101.

Bermejo, "La globalización del crimen organizado", 102.

Bermejo, "La globalización del crimen organizado", 102. 
que constituyen la "sociedad incivil", validos de la economía mundializada, la apertura de fronteras, del libre mercado y de los avances en comunicaciones y tecnología, han adquirido capacidades más poderosas y destructivas. ${ }^{7}$

Con la intención de promover la cooperación internacional, en la Convención de Palermo se hizo la distinción entre grupo delictivo organizado y grupo estructurado. Se definió el primero como:

[...] un grupo estructurado de tres o más personas que exista durante cierto tiempo y que actúe concertadamente con el propósito de cometer uno o más delitos graves o delitos tipificados con arreglo a la presente Convención con miras a obtener, directa o indirectamente, un beneficio económico u otro beneficio de orden material. ${ }^{8}$

$\mathrm{Y}$ al segundo como:

[...] un grupo no formado fortuitamente para la comisión inmediata de un delito y en el que no necesariamente se haya asignado a sus miembros funciones formalmente definidas ni haya continuidad en la condición de miembro o exista una estructura desarrollada. ${ }^{9}$

La convención también estableció que el delito del tráfico ilícito de drogas se consideraría de carácter transnacional cuando se cometiera en más de un Estado; cuando se cometiera en un solo Estado, pero su dirección, control, planeación y preparación se efectuara en otro Estado; cuando se cometiera por un grupo delictivo organizado que ejecuta sus actividades criminales en más de un Estado, y cuando los efectos del delito tuviera efectos sustanciales en otro Estado. ${ }^{10}$

Para los Gobiernos del hemisferio occidental, los cambios ocasionados por el fenómeno de la globalización, de los que surgen nuevos actores y amenazas transnacionales, motivaron que los ministros de Relaciones Internacionales de los países asociados en la Organización de Estados Americanos (OEA) se reunieran en el año 2002 en la ciudad de Bridgetown (Barbados), con el propósito de analizar el significado,

\footnotetext{
Organización de Naciones Unidas [ONU], Convención de las Naciones Unidas contra la delincuencia organizada transnacional y sus protocolos (Nueva York: Autor, 2004), iii.

8 ONU, Convención de las Naciones Unidas contra la delincuencia, 5.

9 ONU, Convención de las Naciones Unidas contra la delincuencia, 5.

10 ONU, Convención de las Naciones Unidas contra la delincuencia, 6.
} 
los alcances y la proyección del concepto de seguridad hemisférica y desarrollar enfoques comunes que permitan garantizar la paz y la seguridad en el hemisferio.

A manera de conclusión, la Declaración de Bridgetown sostuvo que el enfoque de seguridad para el hemisferio era multidimensional, pues consideraba la existencia de amenazas provenientes de actores convencionales y no tradicionales, y de factores de inseguridad de carácter también multidimensional. ${ }^{11}$

La Declaración sobre seguridad de las Américas, emitida el 28 de octubre de 2003 en Ciudad de México (México), contempló que, además de las convencionales, la región se verá afectada por nuevas amenazas como la corrupción, la delincuencia organizada transnacional, el lavado de activos, el problema mundial de las drogas, el terrorismo, el tráfico ilícito de armas y las conexiones entre ellos. En aras de garantizar la seguridad hemisférica, ello exige la adopción de mecanismos de cooperación bilaterales y regionales en seguridad y defensa. ${ }^{12}$

Las preocupaciones, los riesgos y los desafíos a la seguridad internacional se hacen cada vez más complejos, al observarse la convergencia de intereses y las relaciones entre organizaciones terroristas y del tráfico ilícito de drogas e insurgencias, cuyas capacidades de adaptación, diversificación y acción en red les permiten tener un alcance global, que vulnera la soberanía y la estabilidad de los Estados y del sistema internacional. ${ }^{13}$

El narcotráfico desafía la capacidad de los Estados, hasta los más poderosos, para controlarlo, poniendo de presente la pérdida de soberanía que el proceso de globalización implica. El narcotráfico evidencia no sólo los alcances de la progresiva conformación de un mercado mundial, sino que, así mismo, ocupa un lugar central en la agenda de seguridad global que se ha ido conformando en los últimos años. ${ }^{14}$

11 Organización de los Estados Americanos [OEA], Declaración de Bridgetown: enfoque multidimensional de la seguridad hemisférica (Bridgetown, 4 de junio de 2002).

12 Organización de los Estados Americanos [OEA], Conferencia especial sobre seguridad Ser. K/ XXXVIII (Ciudad de México, 28 de octubre 2003).

13 James G. Stavridis, "Foreword" en Convergence Illicit Networks and National Security in the Age of Globalization, eds. Michael Miklaucic y Jacqueline Brewer (Washington: Center for Complex Operations Institute for National Strategic Studies, 2013), vii.

14 Diana Marcela Rojas, "Panel 5: Las organizaciones del narcotráfico y las dinámicas internacionales" en La VIII cátedra anual de historia "Ernesto Restrepo Tirado": análisis histórico del narcotráfico en Colombia, (Bogotá: Museo Nacional de Colombia, 2014), 372-373. 


\section{La relación transnacional entre los carteles colombianos y mexicanos}

La relación criminal entre las organizaciones colombianas y mexicanas del tráfico ilícito de drogas surge como resultado del control del comercio y de la distribución que los carteles colombianos habían alcanzado hacia la década del setenta en Florida (Estados Unidos) y que, para finales de 1980, según la Agencia Antidrogas de Estados (en adelante, DEA) correspondió a 50 toneladas. ${ }^{15}$

Desde Cayo Norman, en Florida, por intermedio del trabajo de Carlos Lehder, el cartel de Medellín logró instalar el lugar adecuado para la introducción, por vía aérea y marítima, de la cocaína de Pablo Escobar y los hermanos Ochoa al mercado norteamericano. ${ }^{16}$ Sin embargo, con el golpe asestado por la DEA a la base en Cayo Norman, los capos colombianos buscaron otras vías por las que pudieran continuar sus operaciones. Una de ellas fue la ruta México-Estados Unidos.

Establecido el territorio mexicano como una de sus rutas, el cartel de Medellín contactó al narcotraficante mexicano Pablo Acosta Villareal, el Zorro de Ojinagua. Para dar inicio a la operación, el cartel de Medellín designó en 1984 a Alberto Ochoa Soto como coordinador de los envíos a Ojinagua, con lo que se abrieron las relaciones entre los narcotraficantes de México y Colombia. De aquí surgió Amado Carrillo, quien, después de hacer asesinar a Acosta Villareal, tomó el control de las operaciones y el vínculo con Alberto Ochoa, del que sacó el mayor provecho para conocer en detalle el negocio del narcotráfico internacional. ${ }^{17}$

El control de las rutas y la distribución de la coca por parte de los colombianos llamó la atención de los capos mexicanos, quienes acudieron al hondureño José Ramón Matta Ballesteros para tramitar el primer encuentro entre el jefe del cartel de Guadalajara, Miguel Ángel Félix Gallardo, el Jefe de los Jefes; Pablo Escobar Gaviria, el Patrón, y Gonzalo Rodríguez Gacha, el Mexicano, del cartel de Medellín. De común acuerdo ante la necesidad de establecer una ruta alterna al Caribe, analizaron las condiciones geográficas de Honduras y la vulnerabilidad institucional para hacer de este país el puente para introducir a los Estados Unidos la cocaína producida

15 Adolfo Atehortúa y Diana Rojas, "El narcotráfico en Colombia. Pioneros y capos", Historia y Espacio 4, núm. 31 (enero 2008): 8.

16 Eduardo Sáenz, "Entre Carlos Lehder y los vaqueros de la cocaína. La consolidación de las redes de narcotraficantes colombianos en Miami en los años 70", Cuadernos de Economía 30, núm. 54 (enero 2011): 105.

17 Ana Arana, "El Pablo Escobar de México", El Tiempo, Secc. Archivo, 20 de octubre de 1996, https://www. eltiempo.com/archivo/documento/MAM-549343 (acceso febrero 1, 2020). 
en Colombia. La conveniencia del acuerdo para los narcos de Medellín residió en las conexiones que Félix Gallardo poseía con los círculos políticos, financieros y de seguridad mexicanos, lo que favorecería las inversiones y el lavado de dinero de la organización en este país; ${ }^{18}$ mientras, a Félix Gallardo el acuerdo le representaría el reconocimiento como el mayor narcotraficante de cocaína de México. ${ }^{19}$

La relación entre los dos carteles no duró lo esperado, pues a finales de 1987 fue capturado Miguel Ángel Félix Gallardo, a quien se responsabilizó por el crimen del agente de la DEA Enrique Camarena. Recibió una condena de cuarenta años en prisión, lo que produjo la desmembración del cartel en tres grupos: el cartel de Tijuana, liderado por los hermanos Arellano Félix; el cartel de Sinaloa, dirigido por el Chapo Guzmán y el Güero Palma, y el cartel de Juárez, bajo responsabilidad de Amado Carrillo, el Señor de los Cielos. ${ }^{20}$

La captura de Félix Gallardo no afectó mayormente la decisión adoptada por los dos carteles. En la práctica, esta ruta redujo y garantizó el progreso de la operación, al punto que, para el año de 1991, un 50 \% de la cocaína producida en Colombia que transitaba hacia Estados Unidos pasaba por México. ${ }^{21}$

La necesidad de alianzas con los carteles mexicanos llevó a Pablo Escobar a entablar contacto en 1988 con Amado Carrillo Fuentes, el Señor de los Cielos, capo de cartel de Juárez, que le ofreció la ruta marítima conocida como la Fanny y la flotilla de aviones 727 , lo que mejoró su situación en razón a los frecuentes golpes propinados por la DEA a las aeronaves del cartel en Costa Rica, Nicaragua y Panamá. Para la operación, el cartel nombró a John Jairo Velásquez, Popeye, responsable de las transacciones con el cartel de Juárez. Carrillo, conocedor de la posición de ventaja de Escobar, le exigió que los pagos se efectuaran en cocaína y le dieran acceso al

18 Luis Astorga, "México, Colombia y las drogas ilegales: variaciones sobre un mismo tema" en La VIII cátedra anual de historia "Ernesto Restrepo Tirado": análisis histórico del narcotráfico en Colombia (Bogotá: Museo Nacional de Colombia, 2014), 50.

19 Lau Almaraz, "¿Quién es Miguel Ángel Félix Gallardo?", https://news.culturacolectiva.com/mexico/quienes-miguel-angel-felix-gallardo/ (acceso febrero 1, 2020).

20 Almaraz, “¿Quién es Miguel Ángel Félix Gallardo?”, 52.

21 "La decadencia de los cárteles colombianos dejó a los mexicanos al mando de la coca Arturo Beltrán Leyva, muerte y escarnio de un "jefe de jefes", La Nueva España, 7 de marzo de 2010, https://www.lne.es/ internacional/2010/03/07/decadencia-carteles-colombianos-dejo-mexicanos-mando-coca-arturo-beltranleyva-muerte-escarnio-jefe-jefes/882896.html (acceso febrero 1, 2020). 
mercado de Atlanta, Chicago, Oklahoma y Seattle. Esta demanda constituyó el punto de partida del declive de los carteles colombianos en el negocio de la droga. ${ }^{22}$

La batalla contra los carteles del narcotráfico se sintió en Colombia. La ofensiva contra los carteles de Medellín y Cali arrojó sus primeros resultados con la entrega de Pablo Escobar a las autoridades colombianas el 19 de junio de 1991. La detención de Escobar en la cárcel La Catedral, de Itagüí, fue aprovechada por Amado Carrillo, pues, en alianza con el cartel de Cali, le robó doce toneladas de cocaína a Escobar, situación que selló el fin de la criminal sociedad. La alianza con el cartel de Cali por medio de Miguel Rodríguez Orejuela le permitió a Carrillo ubicarse a la cabeza de las organizaciones del narcotráfico de Sinaloa. ${ }^{23}$ El vínculo entre estas dos organizaciones del crimen transnacional se extendió hasta el año de 1993, cuando los de Cali atentaron contra el Señor de los Cielos y su familia en el restaurante Bali Hai, de Ciudad de México. ${ }^{24}$

En Colombia, después de la fuga de Pablo Escobar de la cárcel La Catedral en 1992, se desató la persecución de las autoridades al capo de Medellín. Los golpes asestados a sus lugartenientes condujeron al capo a refugiarse en una sencilla residencia, lugar donde fue ubicado y, tras un intercambio de disparos, fue muerto el día 2 de diciembre de 1993.

Liberados de la competencia del cartel de Medellín y ante la ruptura con Amado Carrillo, el cartel de Cali buscó contactos con Juan García Abrego, el Barón del Golfo, capo del cartel de Matamoros, quien, en compañía de su tío Juan Nepomuceno, poseía excelentes relaciones con el Gobierno por intermedio de Raúl Salinas Lozano. Los hermanos Rodríguez Orejuela le ofrecieron un 50 \% de las utilidades por el transporte de cocaína desde la frontera sur de México hasta Texas. El acuerdo le permitía al cartel de Matamoros dejar de ser una organización criminal subsidiaria de los carteles colombianos y empezar a ser reconocida como una organización de importancia en el mercado transnacional. A partir de este convenio, la organización se transformó en el cartel del Golfo. ${ }^{25}$

22 Bruce Bagley, "Carteles de la droga: de Medellín a Sinaloa", Criterios. Cuadernos de Ciencias Jurídicas y Política Internacional 4, núm. 1 (enero 2011), 239.

23 Astorga, "México, Colombia y las drogas ilegales", 53.

24 Juliana Fregoso, "El día que un capo mexicano le robó 12 toneladas de cocaína a Pablo Escobar", https:// www.infobae.com/america/mexico/2018/09/02/el-dia-que-un-capo-mexicano-le-robo-12-toneladasde-cocaina-a-pablo-escobar/ (acceso febrero 1, 2020).

25 Eduardo Guerrero, "El dominio del miedo", https://www.nexos.com.mx/?p=21671 (acceso febrero 1, 2020). 
Su protagonismo delictivo y el ascenso de Zedillo al poder marcaron el inicio de la decadencia del cartel. A la pérdida del padrinazgo gubernamental y de la complicidad de las autoridades se sumó el interés de la DEA por asestar un golpe estructural a los carteles, intención que se concretó con la captura de Juan García Abrego el 14 de enero de 1996 y su inmediata extradición a Estados Unidos.

Con la captura de García, Osiel Cárdenas asumió el liderazgo de la organización criminal y promovió grandes cambios en su funcionamiento, al incorporar en sus filas un grupo de exmilitares del que, a manera de ejército personal, se valió para imponer normas y protocolos para la operación. La incorporación de estos y sus procedimientos trascendió la operación del cartel: se adoptaron métodos de reclutamiento y entrenamiento y se extendió el control a todas las actividades criminales en distintas ciudades. Las ansias de poder dieron paso a la conformación de Los Zetas. De empresas familiares jerarquizadas, restringidas a un espacio territorial, pasaron a ser organizaciones horizontales con brazos armados profesionalizados, con espíritu expansionista y con intereses en varias actividades criminales. ${ }^{26}$

A la agresiva visión de los nuevos carteles mexicanos se unió la captura de los capos del cartel de Cali. La ofensiva de las autoridades colombianas y estadounidenses, que ahora se fijaban en la familia Rodríguez y sus secuaces, dio con la captura de Gilberto Rodríguez, el Ajedrecista, el 9 de junio de 1995, seguido de las entregas de Henry Loaiza Ceballos, el Alacrán, el 19 de junio, y Víctor Patiño Fómeque, el Químico, el 24 de junio. Los golpes de las autoridades colombianas continuaron con la captura de José Santacruz Londoño el 4 de julio y la posterior entrega de Phanor Arizabaleta Arzayús, el 8 de julio. La debacle del cartel de Cali culminó con la entrega de Pacho Herrera el 1 de septiembre de 1996. ${ }^{27}$

La decadencia de los carteles colombianos y la transformación de los carteles mexicanos, con sus ansias de poder y expansión, provocaron la transición del mando. El dominio del negocio de la cocaína quedó en manos de los violentos y ambiciosos carteles mexicanos, que buscaban hacerse al control de todas las actividades del circuito criminal. De esta forma, los nuevos carteles se adaptaron a las circunstancias a manera de efecto globo, como lo describe Duncan Devill:

Guerrero, "El dominio del miedo".

27 "Acabaron con el cartel de Cali", El Tiempo, 7 de agosto de 1995, https://www.eltiempo.com/archivo/ documento/MAM-384126 (acceso febrero 1, 2020). 
Cuando de manera conjunta los esfuerzos policiales colombianos e internacionales lograron controlar las actividades de los carteles colombianos de la coca en la década de 1990, los carteles cambiaron sus roles dentro de la cadena de suministro, y las operaciones de distribución migraron a México. El "efecto globo" no es nuevo. ${ }^{28}$

\section{La hegemonía mexicana: convergencia del crimen transnacional}

Con el ocaso de las antiguas generaciones de narcotraficantes surgieron tanto en Colombia como en México organizaciones criminales que, al priorizar sus intereses económicos y comerciales, efectuaron pactos con organizaciones insurgentes, terroristas y del crimen en el hemisferio y fuera de él. Se configuró el fenómeno de la convergencia, entendida como la alianza entre las organizaciones del crimen transnacional, la insurgencia, el terrorismo y la delincuencia organizada que, a modo de redes, desde un enfoque multidimensional, comparten intereses, tácticas y procedimientos, despliegan sus actividades desde regiones en conflictos prolongados ${ }^{29}$ y evolucionan, para volverse más complejas, volátiles y desestabilizadoras. ${ }^{30}$

Los carteles mexicanos consolidaron su hegemonía en el negocio de la cocaína e iniciaron, a partir del nuevo siglo, la disputa por la producción, las rutas y la comercialización de los narcóticos lo que los condujo a establecer alianzas inimaginables. En Colombia los carteles de Juárez, Tijuana, Sinaloa, Nueva Generación y del Golfo extendieron sus tentáculos criminales hacia organizaciones insurgentes como las FARC, el Ejército de Liberación Nacional (en adelante, ELN), los GAO y bandas criminales (en adelante, bacrim).

La disputa por las ganancias provenientes de tráfico de narcóticos, que se calculan por lo menos entre 15 mil y 25 mil millones de dólares anuales, son el motivo de la sangrienta lucha entre los siete principales carteles mexicanos (de Sinaloa, del

28 Phil Williams, "Lawlessness and Disorder: An Emerging Paradigm for the 21 Century" en Convergence Illicit Networks and National Security in the Age of Globalization, eds., Michael Miklaucic y Jacqueline Brewer (Washington: Center for Complex Operations Institute for National Strategic Studies, 2013), 18.

29 Felipe Barrera, Ángel Riveros y Javier Ospina, "Convergencia de la seguridad en Colombia: terrorismo y delincuencia organizada" en Escenarios y desafios de la seguridad multidimensional en Colombia, ed., Carlos Álvarez (Bogotá: Escuela Superior de Guerra, 2017), 591.

30 Williams, "Lawlessness and Disorder", 19. 
Golfo, los Zetas, de Tijuana, de Juárez, Beltrán Leyva y de la Familia Michoacana) y docenas de bandas menores. ${ }^{31}$

Los vínculos de tan tenebrosa y destructiva relación entre las FARC y los carteles mexicanos se remontan al año de 1999, con la participación del médico Carlos Ariel Charry Guzmán en el tráfico de cocaína producida por el Bloque Sur en la zona de distensión promovida por el presidente Andrés Pastrana Arango. ${ }^{32}$ Desde San Vicente del Caguán (Caquetá), en cumplimiento de las directrices emitidas en la Séptima conferencia guerrillera de 1982,33 la organización insurgente planeó el cultivo, la producción y el transporte de la cocaína hacia México. El vínculo les permitía a los carteles mexicanos acceder a la organización que, desde el año 1990, controlaba gran parte de la producción de cocaína del país, con la cual garantizaba su crecimiento y operación. ${ }^{34}$

Para las autoridades colombianas, con la captura del Médico se puso en evidencia la existencia de una "organización criminal dedicada al tráfico de estupefacientes a nivel nacional e internacional", 35 la cual era liderada por la familia Charry Guzmán, que mantenía estrechos vínculos con el Secretariado de las FARC en la zona de distensión. Igualmente, se estableció que la organización mexicana correspondía al cartel de Tijuana, de los hermanos Arellano Félix, con quienes se conspiró para introducir a Estados Unidos grandes cantidades de narcóticos procedentes de Colombia. ${ }^{36}$

Los vínculos de los carteles mexicanos con las FARC se fueron ampliando en el nuevo siglo, al entablar, hacia el año 2000, contactos con el cartel de Sinaloa, en cabeza de Ismael Zambada, el Mayo. Los capos de Sinaloa establecieron comunicación con Luis Eduardo Carvajal Pérez, el Rambo, cabecilla de la columna móvil Daniel Aldana, de las FARC, a quien se le reconoce como la persona que definió la ruta marítima de la provincia de Esmeraldas (Ecuador), abrió el mercado a los carteles mexicanos en el Pacífico, participó en la adaptación de las lanchas rápidas como

31 Bagley, "Carteles de la droga: de Medellín a Sinaloa", 235.

32 Colprensa, "Deportan desde México a alias Carlos, el 'médico' de las FARC", El País, Secc. Judicial, 7 de diciembre de 2011, https://www.elpais.com.co/judicial/deportan-desde-mexico-a-alias-carlos-el-medicode-las-farc.html (acceso febrero 1, 2020).

33 Centro Nacional de Memoria Histórica, Guerrilla y población civil. Trayectoria de las FARC 1949-2013, 3a ed. (Bogotá: Autor, 2014), 108.

34 Mario Aguilera, "Las FARC: auge y quiebre de su modelo de guerra". Análisis político 26, núm. 77 (enero 2013): 94 .

35 Colombia, Corte Suprema de Justicia, Sentencia 31526 de 27 de mayo de 2009, M. P. Javier Zapata Ortiz.

36 Colombia, Corte Suprema de Justicia, Sentencia 31526 de 27 de mayo de 2009. 
semisumergibles y fue el eje de las operaciones del narcotráfico de las FARC en el sur del país. ${ }^{37}$

En 2007, la operación se fortaleció, cuando vinculó como enlace al colombiano Jorge Milton Cifuentes Villa, Jota, hermano del expiloto de Pablo Escobar, ${ }^{38}$ quien, desde su base en Ecuador, negociaba la cocaína con las FARC.

Con la muerte del capo del cartel de los Beltrán Leyva, Arturo Beltrán, en diciembre de 2009, su hermano Héctor asumió el control de la organización y fijó sus esfuerzos en la consolidación del control de la producción de cocaína en el Pacífico colombiano, para lo cual designó al reconocido narcotraficante Édgar Valdez Villareal, la Barbie, para que dirigiera la labor de inserción de la red mexicana en el país. Se designó a Julio César Piña Soberanís, Julio, como emisario del cartel y por su intermediación se fueron instalando los enlaces con los Frentes 6, 29, 30 y 48 de las FARC. ${ }^{39}$ Para el intercambio de drogas y armas se nombró a Mario Sánchez Zabaleta y Dionisio Jiménez Sinisterra y, para los frentes, a Dennis Alvarino Gómez, el Negrito, como enlace con Luis Carlos Neiva Neiva, cabecilla del Frente 30 de las FARC. ${ }^{40}$

En Colombia, la confrontación por la producción de cocaína en los territorios dejados por las FARC y la disputa por las rutas y el negocio del narcotráfico ocasionaron la intervención directa de los carteles mexicanos en el país. Con la llegada de los aztecas en 2012, el objetivo se dirigió a poner orden entre las organizaciones criminales que ponían en peligro el suministro de cocaína para el mercado internacional. ${ }^{41}$

Los emisarios de los carteles mexicanos que arribaron al Pacífico colombiano se dieron a la tarea de concretar alianzas entre las estructuras de las FARC, bandas criminales

37 "Quien es Rambo el segundo ex FARC capturado para extradición", El Tiempo, 5 de julio de 2018, https:// www.eltiempo.com/justicia/conflicto-y-narcotrafico/quien-es-rambo-el-segundo-exfarc-capturadopor-extradicion-239694 (acceso febrero 1, 2020).

38 Alan Feuer, "Los vínculos entre el Chapo y las FARC, expuestos a través de una grabación secreta", The New York Times, Secc. The New York Times en español, 14 de diciembre de 2018, https://www.nytimes.com/ es/2018/12/14/espanol/el-chapo-cocaina-juicio-farc.html (acceso febrero 1, 2020).

39 María del Rosario Arrázola y Sebastián Jiménez Herrera, "Las FARC y los carteles mexicanos", El Espectador, Secc. Nacional, 4 de julio de 2012, https://www.elespectador.com/noticias/nacional/farc-y-los-cartelesmexicanos-articulo-357264 (acceso febrero 1, 2020)

40 Sebastián Jiménez, "Las FARC y los cárteles mexicanos cultivan al menos 10 años de relación", Expansión, Secc. Internacional, 01 de septiembre de 2010, https://expansion.mx/mundo/2010/09/01/las-farc-y-loscarteles-mexicanos-cultivan-anos-de-relacion (acceso febrero 1, 2020).

${ }^{41}$ James Bargent, "¿Cuál es la estrategia de los carteles mexicanos para la Colombia pos-FARC?", InSigth crime, Secc. Análisis, 27 de febrero de 2018, https://es.insightcrime.org/noticias/analisis/cual-es-la-estrategiade-los-carteles-mexicanos-para-la-colombia-pos-farc/ (acceso febrero 1, 2020). 
y organizaciones narcotraficantes del país, para articular y unir capacidades para el tráfico transnacional de cocaína..$^{42}$ La relación de estas organizaciones permitió que desde la región se asegurara el envío, en lanchas rápidas, buques y sumergibles, por el océano Pacífico hacia Centro américa de más de tres toneladas de cocaína al mes. ${ }^{43}$

Las alianzas transnacionales entre organizaciones criminales se complementaron con la participación del cartel mexicano Jalisco Nueva Generación, que entabló acuerdos con las FARC por intermedio de Nemesio Oseguera Cervantes, el Mencho. Para su operación, además de la compra de cocaína a las FARC, el cartel instaló sus propios laboratorios en Tumaco (Nariño), en proximidades a la frontera con Ecuador. La compra de la cocaína producida en el Pacífico era transportada por vía marítima, cuyos puntos de reabastecimiento en alta mar eran las islas Galápagos y la isla Coco. ${ }^{44}$

De aquí se puede inferir que los frentes de las FARC que delinquen en el suroccidente del país han designado sus esfuerzos al desarrollo de cada uno de los eslabones del narcotráfico, desde el cultivo ilícito a la distribución internacional, y al empleo del terrorismo para atacar a las autoridades que se oponen a sus intereses criminales.

La firma del Acuerdo general para el fin del conflicto y el establecimiento de una paz estable y duradera entre el gobierno del expresidente Juan Manuel Santos y las FARC, en 2016, que condujo a la desmovilización y reincorporación de los guerrilleros a la sociedad colombiana, a su vez conllevó la conformación de grupos disidentes que heredaron los vínculos con el narcotráfico y persisten en hacer la guerra a los colombianos. El nexo de los principales disidentes con los carteles mexicanos existió desde el mismo momento en que se puso en marcha el proceso de paz.

Para los carteles mexicanos, la desmovilización de las estructuras de las FARC con las que mantenían lazos no podía perderse. La modificación de las circunstancias obligó a los aztecas a adaptarse y a restablecer los contactos con las nuevas organizaciones con las que, además de liderar el vínculo, lo complementó con la vigilancia de la producción y el suministro de armas a los grupos locales, a cambio de los servicios de seguridad y producción. ${ }^{45}$

42 Arrázola y Herrera, "Las FARC y los carteles mexicanos".

43 Jiménez, "Las FARC y los cárteles mexicanos cultivan al menos 10 años de relación".

44 "Desarticulan en Colombia a banda ligada a 'El Mayo' y 'El Mencho", Excelsior, 1 de marzo de 2017, https:// www.excelsior.com.mx/global/2017/03/01/1149484 (acceso febrero 1, 2020).

45 "Así cambió la relación de los narcos mexicanos con los grupos criminales colombianos en el mercado de la droga", Infobae, 16 de abril de 2019, https://www.infobae.com/america/colombia/2019/04/16/ 
La descomposición ideológica de las organizaciones alzadas en armas como consecuencia del nexo con el narcotráfico las llevó a establecer acuerdos con grupos criminales. Es así como en varias regiones del país hicieron pactos entre frentes de las disidencias de las FARC con integrantes del cartel del Golfo, con el ELN, con autodefensas y con estructuras mexicanas.

Desde el año 2016, cuando se dieron a conocer las estructuras disidentes de las FARC, las preocupaciones por la seguridad para los colombianos se incrementaron, al activarse la disputa por los territorios en los que se desarrollaban actividades de cultivos ilícitos y que fueron dejados por la antigua guerrilla. Las fracciones que persisten en su intención de tomarse el poder por la vía armada, contradictoriamente, mantienen vínculos estrechos con organizaciones del crimen transnacional, entre los que se encuentran los carteles mexicanos y grupos criminales al interior del país.

El principal cabecilla de las disidencias, Miguel Botanche Santillana, Gentil Duarte, quien dirige el Séptimo Frente de las antiguas FARC en los departamentos de Meta, Caquetá y Vichada, reactivó las relaciones con el cartel de Tijuana utilizando al ganadero alias Lámpara. Para el cabecilla, el control de la producción y las rutas son factores determinantes, por lo que se hace esencial restablecer el tráfico de cocaína hacia Estados Unidos por la ruta Venezuela-Centroamérica que otrora manejaba alias Evaristo, quien fue extraditado a Estados Unidos en 2013. ${ }^{46}$

En el sur del país, las relaciones con los carteles mexicanos se mantienen con la disidencia del Frente Oliver Sinisterra, de las FARC. Su cabecilla, Walter Patricio Arizala, Guacho, durante varios años se ligó con los delegados del cartel de Sinaloa. La sociedad de estas estructuras permitió el envío de toneladas de cocaína a los Estados Unidos por el océano Pacífico. En esta región, que produce un 16 \% de la cocaína del país, el Frente Oliver Sinisterra ha adelantado una campaña de intimidación y asesinato de líderes, indígenas y campesinos que apoyan la sustitución de cultivos de uso ilícito. De acuerdo con Néstor Humberto Martínez, exfiscal general de la Nación, alias Guacho se ha convertido en el brazo armado del cartel de Sinaloa en el país, lo que constituye un problema geopolítico en la región. ${ }^{47}$

asi-cambio-la-relacion-de-los-narcos-mexicanos-con-los-grupos-criminales-colombianos-en-el-mercadode-la-droga/ (acceso febrero 1, 2020).

46 Jorge Bermúdez, "Peligrosa alianza de disidencia de las FARC con cartel de Tijuana", https://noticias.canall. com.co/nacional/peligrosa-alianza-disidencia-las-farc-cartel-tijuana/ (acceso febrero 1, 2020).

47 Daniel Zabala, "Guacho' y los vínculos que tenía con el cartel de Sinaloa" https://www.lafm.com.co/ colombia/guacho-y-los-vinculos-que-tenia-con-el-cartel-de-sinaloa (acceso febrero 1, 2020). 
A los de Sinaloa, la presencia en Tumaco de otras estructuras del crimen organizado, como las Guerrillas Unidas del Pacífico (GUP), de la que forman parte las cabecillas David, Contador y su socio Mario Lata, que promovieron la guerra contra Guacho, les causó gran preocupación, debido a la disminución de la producción de cocaína a raíz de la confrontación entre ellos. ${ }^{48}$

Tumaco, en el departamento de Nariño, es una de las zonas preferidas por los mexicanos por tener cultivos de coca y rutas de tráfico por la costa pacífica [... . . Los carteles mexicanos envían pequeños grupos de emisarios a Colombia para cumplir un papel de intermediación con los narcotraficantes locales y actores armados, además de llegar a comprobar la calidad del estupefaciente que van a comprar y verificar las rutas de tráfico. ${ }^{49}$

La persistencia del fenómeno de la convergencia del crimen transnacional con organizaciones insurgentes, grupos armados organizados y su extensión transfronteriza en el hemisferio se reforzó con la relación entre el cartel de Sinaloa y las disidencias de las FARC por intermedio de Sauxis Paucis Hernández Solarte (Jesús Santrich), Iván Márquez y Marlon Marín para el envío en el año 2019 de más de diez toneladas de cocaína a Estados Unidos. ${ }^{50}$ La seguridad de la región se vio aún más alterada tras conocerse que, a la convergencia de los carteles mexicanos de Sinaloa con las FARC, se sumaban las relaciones entre Santrich, el cartel de Los Soles, el presidente de Venezuela, Nicolás Maduro, y el capo mexicano Rafael Caro Quintero. Los antecedentes de la relación entre Santrich y Caro Quintero se remontan al año 2016, cuando movieron varias toneladas de cocaína de Colombia a Chicago, vía Sonora y Phoenix..$^{51}$

Las ganancias del narcotráfico condujeron a las FARC a establecer acuerdos con estructuras criminales. En el departamento de Córdoba, en reunión efectuada en

48 Julián Gabriel Parra, "Los cuatro capos que mandan en Tumaco", Las2Orillas, Secc. Especiales, 18 de septiembre de 2019, https://www.las2orillas.co/los-cuatro-capos-que-mandan-en-tumaco/ (acceso febrero $1,2020)$.

49 "Así cambió la relación de los narcos mexicanos con los grupos criminales colombianos en el mercado de la droga", Infobae.

50 "Iván Márquez' conocía al emisario del cartel de Sinaloa que negoció con 'Santrich", Pulso, 1 de septiembre de 2019, https://www.pulzo.com/nacion/vinculos-farc-con-cartel-sinaloa-PP759393 (acceso febrero 1, 2020).

51 Rodrigo Gutiérrez, "Los nexos de Nicolás Maduro con Rafael Caro Quintero, según la DEA", La silla rota, Secc. Nación, 31 de marzo de 2020, https://lasillarota.com/nacion/los-nexos-de-nicolas-maduro-conrafael-caro-quintero-segun-la-dea-nicolas-maduro-maduro-venezuela-caro-quintero/376164 (acceso febrero 1, 2020). 
los límites de los municipios de Tierralta y Carepa en 2014, por intermedio de Jhoverman Sánchez Arroyabe, el Manteco, y alias Gavilán se lograron arreglos entre el Frente 18 de las FARC y los integrantes del clan Úsuga. ${ }^{52}$ Más adelante, el Manteco amplió las alianzas de las disidencias de las FARC con estructuras de las Autodefensas Gaitanistas de Colombia (AGC), con el propósito de asegurar la operación en el departamento de Antioquia. Los pactos permitieron el aumento de los cultivos ilegales de coca, la consolidación del Urabá antioqueño y chocoano como corredor estratégico para el tráfico de cocaína y de migrantes hacia Estados Unidos y el incremento de la minería ilegal en el medio y bajo Atrato y el Bajo Cauca antioqueño. ${ }^{53}$

El pacto con los gaitanistas era un objetivo primordial que las FARC habían considerado en el plan del área Nudo de Paramillo (ANUPA) y que debía concretar para trabajar en la zona. Para los guerrilleros Pastor Alape, Román Ruiz, Rubén o Manteco y Darlinson (conocidos así por sus alias) la relación debía contener un alto al fuego, la definición de territorios, el intercambio de información y material de guerra y el respeto por parte de los gaitanistas a las normas dispuestas por las FARC en sus territorios de injerencia. ${ }^{54}$ Respecto a la producción de cocaína, definieron elevar los precios a los productores de base y la promoción de las FARC y los gaitanistas como aliados.

Los esfuerzos por avanzar en el cumplimiento de lo acordado no duraron mucho, pues dos años después se registraron combates, asesinatos y desplazamientos de población asentada sobre las regiones del Urabá antioqueño y chocoano y Bajo Cauca antioqueño. La confrontación entre las FARC y el ELN contra los gaitanistas dejó en evidencia la crisis de lo pactado. ${ }^{55}$

De esta manera, en varios sectores de la geografía nacional se fueron fraguando pactos entre bandas criminales y las FARC o entre el ELN y las autodefensas. Las motivaciones para dichas alianzas incluyen la definición de roles en los eslabones del narcotráfico. Los acuerdos inimaginables se presentaron entre el Bloque Libertadores

52 Colprensa, "Gavilán' de 'los Urabeños' y 'Manteco' de las FARC se reunieron: general Pinto", elCOLOMBIANO, Secc. Histórico, 22 de septiembre de 2014, https://www.elcolombiano.com/historico/gavilan_y_el_manteco_se_reunieron_general_pinto-DFEC_312144 (acceso febrero 1, 2020).

53 "Acuerdo entre FARC y 'Gaitanistas' está en crisis: 'Rubén El Manteco", Verdad abierta, 17 de abril de 2016, https://verdadabierta.com/acuerdo-entre-farc-y-gaitanistas-esta-en-crisis-ruben-el-manteco/ (acceso febrero 1, 2020).

54 "Acuerdo entre FARC y 'Gaitanistas' está en crisis".

55 Luis Pérez, Informe de riesgo n 010-17 A.I 35 (Bogotá: Defensoría del Pueblo, 2017), 35. 
del Sur y el Frente 29 de las FARC en Nariño; del ELN con Los Rastrojos en Cauca o de disidencias de los paramilitares (Vicente Castaño) con las FARC; nexos entre el Frente 59 con los Rastrojos y los Urabeños en La Guajira y Cesar; el Frente 48 de las FARC con algunas estructuras criminales en Putumayo; del Frente 7 y el ERPAC en Meta; de los Frentes 6, 30 y 57 de las FARC con los Rastrojos en el Pacífico, e incluso entre la Oficina de Envigado y las FARC para provisión de suministros. ${ }^{56}$

Los vínculos entre las diversas expresiones de violencia en el país configuran un escenario de alta peligrosidad e incertidumbre, como lo expone Carlos Negret, defensor del Pueblo, cuando habla de la relación entre estas organizaciones en varios departamentos y el Cartel de Sinaloa, "que es el que financia estas bandas y a las Autodefensas Gaitanistas". ${ }^{57}$ La etérea relación deja entrever la articulación de intereses de los actores involucrados. Con la siembra, la producción, el transporte y la comercialización de la cocaína, cada organización, según el eslabón del narcotráfico que le correspondió, saca provecho. Entre todos se garantizan la seguridad y la logística, en común acuerdo atacan las políticas de sustitución de cultivos de uso ilícito y enfrentan a las autoridades haciendo uso del terrorismo.

Por su parte, en su intención de mejorar las utilidades y asegurar la producción de coca para el mercado internacional, al incursionar en territorio colombiano los carteles mexicanos buscan suprimir los intermediarios para tratar directamente con las organizaciones que controlan las áreas de producción, las redes internas y los puntos de despacho. La estrategia los ha conducido igualmente a adquirir plantaciones de coca y a trasladar ingenieros y agrónomos al país para mejorar los laboratorios e incrementar la producción de las plantas. ${ }^{58}$

Para la coordinación de sus actividades ilícitas, las organizaciones más ambiciosas, como el cartel de Sinaloa, han instalado emisarios en Tumaco, Cali, Bogotá, Bucaramanga, Cartagena y Medellín, cuyas acciones son evaluar la calidad de la cocaína, pagar honorarios, comprar el producto, pagar chantajes y sobornos, dar apoyo logístico ${ }^{59}$ y efectuar la financiación indirecta de campañas por intermedio

56 Carlos Andrés Prieto, "La relación FARC- Bacrim y sus lugares comunes", Fundación Ideas para la paz, Secc. Opinión, 16 de octubre de 2014, http://www.ideaspaz.org/publications/posts/1068 (acceso febrero 1, 2020).

57 Pares, "Carteles mexicanos en Colombia, otro leño encendido", Fundación Paz E reconciliación, Secc. Postconflicto, 16 de agosto de 2019, https://pares.com.co/2019/08/16/carteles-mexicanos-en-colombiaotro-leno-encendido/ (acceso febrero 1, 2020).

58 Bargent, "¿Cuál es la estrategia de los carteles mexicanos para la Colombia pos-FARC?".

59 Bargent, “¿Cuál es la estrategia de los carteles mexicanos para la Colombia pos-FARC?”. 
de las Autodefensas Gaitanistas de Colombia, Los Caparrapos y las disidencias de las FARC y del ELN. ${ }^{60}$

El peligro de la presencia de los carteles mexicanos en el país reside en el traslado de la confrontación que dentro de y entre los carteles se disputan el dominio de cada organización y el control de producción, rutas y mercados. De esta manera, la presencia de los carteles de Sinaloa, Tijuana, Juárez y Jalisco Nueva Generación hacen del ámbito de seguridad un ejercicio cada vez más difuso y complejo.

\section{Conclusiones}

Para el hemisferio occidental, los vínculos entre los carteles mexicanos con las organizaciones insurgentes, criminales y terroristas en Colombia y Venezuela constituyen un problema de seguridad regional. La convergencia de intereses ha logrado permear Gobiernos y áreas estratégicas de la región, lo que activa las alertas en seguridad regional.

Las intenciones de los carteles mexicanos por establecerse en Suramérica ponen en riesgo la estabilidad de las democracias, al incidir en los comicios electorales mediante los actores armados locales. Para este tipo de organizaciones, el ascenso al poder de gobernantes proclives a sus intereses garantizará la estabilidad de su empresa criminal.

En el caso colombiano, considerado el narcotráfico como la principal amenaza a combatir, la presencia de los carteles mexicanos y su actuación en alianza con grupos de insurgentes, terroristas, bandas criminales o grupos armados organizados hacen de la paz un anhelo cada vez más distante. Para estas organizaciones, la existencia de los cultivos de uso ilícito son prenda de garantía, por lo que las políticas de sustitución de cultivos, así como los líderes que las impulsan, se convierten en los primeros objetivos a eliminar.

La globalización, con sus características de interdependencia, apertura de mercados, libre flujo de bienes y capitales y la marginación de la intervención estatal, es una fortaleza de la que se valen las organizaciones del crimen transnacional organizado, pues para las organizaciones del narcotráfico, el escenario en el que se mueven

60 Pares, "Carteles mexicanos en Colombia, otro leño encendido". 
les permite fácilmente trasladar capitales y lavar los dineros producto de sus actos criminales.

La convergencia de las organizaciones del crimen transnacional organizado las hace cada vez más difusas para su catalogación, lo que hace de la adopción de estrategias para su atención algo más complejo; por eso, la articulación de estas, cuyos daños trascienden a la sociedad mundial, exige también la unidad de esfuerzos y cooperación de los Gobiernos en su lucha.

\section{Bibliografía}

"Acabaron con el cartel de Cali". El Tiempo, 7 de agosto de 1995. https://www.eltiempo. com/archivo/documento/MAM-384126 (acceso febrero 1, 2020).

"Acuerdo entre FARC y ‘Gaitanistas' está en crisis: 'Rubén El Manteco”. Verdad abierta, 17 de abril de 2016. https://verdadabierta.com/acuerdo-entre-farc-y-gaitanistas-estaen-crisis-ruben-el-manteco/ (acceso febrero 1, 2020).

"Así cambió la relación de los narcos mexicanos con los grupos criminales colombianos en el mercado de la droga". Infobae, 16 de abril de 2019. https://www.infobae.com/ america/colombia/2019/04/16/asi-cambio-la-relacion-de-los-narcos-mexicanoscon-los-grupos-criminales-colombianos-en-el-mercado-de-la-droga/ (acceso febrero 1, 2020).

"Desarticulan en Colombia a banda ligada a 'El Mayo' y 'El Mencho". Excelsior, 1 de marzo de 2017. https://www.excelsior.com.mx/global/2017/03/01/1149484 (acceso febrero 1, 2020).

"Iván Márquez' conocía al emisario del cartel de Sinaloa que negoció con 'Santrich". Pulso, 1 de septiembre de 2019. https://www.pulzo.com/nacion/vinculos-farc-con-cartelsinaloa-PP759393 (acceso febrero 1, 2020).

"La decadencia de los cárteles colombianos dejó a los mexicanos al mando de la coca Arturo Beltrán Leyva, muerte y escarnio de un "jefe de jefes". La Nueva España, 7 de marzo de 2010. https://www.lne.es/internacional/2010/03/07/decadencia-cartelescolombianos-dejo-mexicanos-mando-coca-arturo-beltran-leyva-muerte-escarnio-jefejefes/882896.html (acceso febrero 1, 2020).

"Quien es Rambo el segundo ex FARC capturado para extradición". El Tiempo, 5 de julio de 2018. https://www.eltiempo.com/justicia/conflicto-y-narcotrafico/quien-es-ramboel-segundo-exfarc-capturado-por-extradicion-239694 (acceso febrero 1, 2020).

Aguilera, Mario. "Las FARC: auge y quiebre de su modelo de guerra". Análisis politico 26, núm. 77 (enero 2013): 94. 
Almaraz, Lau. “¿Quién es Miguel Ángel Félix Gallardo?”. https://news.culturacolectiva. com/mexico/quien-es-miguel-angel-felix-gallardo/ (acceso febrero 1, 2020).

Arana, Ana. "El Pablo Escobar de México". El Tiempo, Secc. Archivo, 20 de octubre de 1996. https://www.eltiempo.com/archivo/documento/MAM-549343 (acceso febrero 1, 2020).

Arrázola, María del Rosario y Sebastián Jiménez Herrera. "Las FARC y los carteles mexicanos". El Espectador, Secc. Nacional, 4 de julio de 2012. https://www.elespectador.com/ noticias/nacional/farc-y-los-carteles-mexicanos-articulo-357264 (acceso febrero 1, 2020).

Atehortúa, Adolfo y Diana Rojas. "El narcotráfico en Colombia. Pioneros y capos". Historia y Espacio 4, núm. 31 (enero 2008): 1-27.

Bagley, Bruce. "Carteles de la droga: de Medellín a Sinaloa". Criterios. Cuadernos de Ciencias Jurídicas y Política Internacional 4, núm 1 (enero 2011), 235.

Bargent, James. "¿Cuál es la estrategia de los carteles mexicanos para la Colombia pos-FARC?". InSigth crime, Secc. Análisis, 27 de febrero de 2018. https://es.insightcrime.org/noticias/ analisis/cual-es-la-estrategia-de-los-carteles-mexicanos-para-la-colombia-pos-farc/ (acceso febrero 1, 2020).

Barrera, Felipe, Ángel Riveros y Javier Ospina. "Convergencia de la seguridad en Colombia: terrorismo y delincuencia organizada" en Escenarios y desafíos de la seguridad multidimensional en Colombia, editado por Carlos Álvarez, 591-641. Bogotá: Escuela Superior de Guerra, 2017.

Bermejo, Fernando. "La globalización del crimen organizado". Eguzkilore 1, núm. 23 (diciembre 2009): 101.

Bermúdez, Jorge. "Peligrosa alianza de disidencia de las FARC con 'Cartel de Tijuana". https:// noticias.canall.com.co/nacional/peligrosa-alianza-disidencia-las-farc-cartel-tijuana/ (acceso febrero 1, 2020).

Centro Nacional de Memoria Histórica. Guerrilla y población civil. Trayectoria de las FARC 1949-2013. 3a ed. Bogotá: Autor, 2014.

Colombia, Corte Suprema de Justicia. Sentencia 31526 del 27 de mayo de 2009. M. P. Javier Zapata Ortiz.

Colprensa. "Deportan desde México a alias Carlos, el 'Médico' de las FARC”. El País, Secc. Judicial, 7 de diciembre de 2011. https://www.elpais.com.co/judicial/deportandesde-mexico-a-alias-carlos-el-medico-de-las-farc.html (acceso febrero 1, 2020).

Colprensa. 'Gavilán' de 'los Urabeños' y 'Manteco' de las FARC se reunieron: general Pinto". elCOLOMBIANO, Secc. Histórico, 22 de septiembre de 2014. https://www. elcolombiano.com/historico/gavilan_y_el_manteco_se_reunieron_general_pintoDFEC_312144 (acceso febrero 1, 2020). 
Cortés, Darío. "Globalización y su relación con el riesgo del lavado de activos". Revista de las Fuerzas Armadas 2016, núm. 234 (enero 2016): 39-45.

Deville, Duncan. "Chapter 4: The Illicit Supply Chain" en Convergence Illicit Networks and National Security in the Age of Globalization, editado por Michael Miklaucic y Jacqueline Brewer, 63-74. Washington: Center for Complex Operations Institute for National Strategic Studies, 2013.

Feuer, Alan. "Juicio al Chapo: los vínculos entre el Chapo y las FARC, expuestos a través de una grabación secreta". The New York Times, Secc. The New York Times en español, 14 de diciembre de 2018. https://www.nytimes.com/es/2018/12/14/espanol/ el-chapo-cocaina-juicio-farc.html (acceso febrero 1, 2020).

Fregoso, Juliana. "El día que un capo mexicano le robó 12 toneladas de cocaína a Pablo Escobar". https://www.infobae.com/america/mexico/2018/09/02/el-dia-queun-capo-mexicano-le-robo-12-toneladas-de-cocaina-a-pablo-escobar/ (acceso febrero 1, 2020).

Guerrero, Eduardo. "El dominio del miedo". https://www.nexos.com.mx/?p=21671 (acceso febrero 1, 2020).

Gutiérrez, Rodrigo. "Los nexos de Nicolás Maduro con Rafael Caro Quintero, según la DEA". La silla rota, Secc. Nación, 31 de marzo de 2020. https://lasillarota.com/ nacion/los-nexos-de-nicolas-maduro-con-rafael-caro-quintero-segun-la-deanicolas-maduro-maduro-venezuela-caro-quintero/376164 (acceso febrero 1, 2020).

Jiménez, Sebastián. "Las FARC y los cárteles mexicanos cultivan al menos 10 años de relación”. Expansión, Secc. Internacional, 1 de septiembre de 2010. https://expansion. mx/mundo/2010/09/01/las-farc-y-los-carteles-mexicanos-cultivan-anos-de-relacion (acceso febrero 1, 2020).

Luis Astorga. "México, Colombia y las drogas ilegales: variaciones sobre un mismo tema" en La VIII cátedra anual de historia "Ernesto Restrepo Tirado": análisis histórico del narcotráfico en Colombia, 40-65. Bogotá: Museo Nacional de Colombia, 2014.

Organización de los Estados Americanos [OEA]. Conferencia especial sobre seguridad Ser. K/ XXXVIII. Ciudad de México, 28 de octubre 2003.

Organización de los Estados Americanos [OEA]. Declaración de Bridgetown: enfoque multidimensional de la seguridad hemisférica. Bridgetown, 4 de junio de 2002.

Organización de Naciones Unidas [ONU]. Convención de las Naciones Unidas contra la delincuencia organizada transnacional y sus protocolos. Nueva York: Autor, 2004.

Pares. "Carteles mexicanos en Colombia, otro leño encendido". Fundación Paz E reconciliación, Secc. Postconflicto, 16 de agosto de 2019. https://pares.com.co/2019/08/16/cartelesmexicanos-en-colombia-otro-leno-encendido/ (acceso febrero 1, 2020). 
Parra, Julián Gabriel. "Los cuatro capos que mandan en Tumaco". Las2Orillas, Secc. Especiales, 18 de septiembre de 2019. https://www.las2orillas.co/los-cuatro-caposque-mandan-en-tumaco/ (acceso febrero 1, 2020).

Pérez, Luis. Informe de riesgo n 010-17 A.I 35. Bogotá: Defensoría del Pueblo, 2017.

Prieto, Carlos Andrés. "La relación FARC- Bacrim y sus lugares comunes". Fundación Ideas para la paz, Secc. Opinión, 16 de octubre de 2014. http://www.ideaspaz.org/ publications/posts/1068 (acceso febrero 1, 2020).

Rojas, Diana Marcela. "Panel 5: Las organizaciones del narcotráfico y las dinámicas internacionales" en La VIII cátedra anual de historia "Ernesto Restrepo Tirado": análisis histórico del narcotráfico en Colombia, 372-373. Bogotá: Museo Nacional de Colombia, 2014.

Sáenz, Eduardo. "Entre Carlos Lehder y los vaqueros de la cocaína. La consolidación de las redes de narcotraficantes colombianos en Miami en los años 70". Cuadernos de economía 30, núm. 54 (enero 2011): 1-22.

Stavridis, James G. "Foreword" en Convergence Illicit Networks and National Security in the Age of Globalization, editado por Michael Miklaucic y Jacqueline Brewer, 7-10. Washington: Center for Complex Operations Institute for National Strategic Studies, 2013.Williams, Phil. "Lawlessness and Disorder: An Emerging Paradigm for the 21 Century" en Convergence Illicit Networks and National Security in the Age of Globalization, editado por Michael Miklaucic y Jacqueline Brewer, 15-37. Washington: Center for Complex Operations Institute for National Strategic Studies, 2013.

Zabala, Daniel. "Guacho' y los vínculos que tenía con el cartel de Sinaloa”. La FM, Secc. Colombia, 21 de diciembre de 2018. https://www.lafm.com.co/colombia/guachoy-los-vinculos-que-tenia-con-el-cartel-de-sinaloa (acceso febrero 1, 2020). 